\title{
Association of the rs1424954 polymorphism of the ACVR2A gene with the risk of pre-eclampsia is not replicated in a Finnish study population
}

\author{
A Inkeri Lokki ${ }^{1,2}$, Miira M Klemetti ${ }^{2,3,4}$, Sanna Heino ${ }^{1,2}$, Leena Hiltunen ${ }^{5}$, Seppo Heinonen ${ }^{6,7}$ and Hannele Laivuori ${ }^{1,2^{*}}$
}

\begin{abstract}
Background: Pre-eclampsia/eclampsia is a common vascular pregnancy disorder associated with high maternal and infant mortality and morbidity worldwide. The role of Activin A and more recently type 2 Activin A receptor (ACVR2A) in the pathogenesis of pre-eclampsia has been the subject of genetic and biochemical research with controversial results.

Findings: We genotyped a candidate pre-eclampsia-associated single nucleotide polymorphism rs1424954 in ACVR2A in three independent study populations of Finnish pre-eclamptic (total $\mathrm{N}=485$ ) and non-pre-eclamptic (total $\mathrm{N}=449$ ) women using pre-designed TaqMan allele discrimination assay and polymerase chain reaction. The possible association of the alleles and genotypes of interest with pre-eclampsia was evaluated using the chi-square test and logistic regression analysis. We found no association of rs1424954 to pre-eclampsia in Finnish patients.

Conclusions: rs 1424954 was not associated to pre-eclampsia in the Finnish study population. We hypothesise that while the gene associates to pre-eclampsia worldwide, the causative polymorphism in ACVR2A may be unique in genetically differing populations. Further research is needed to characterise the haplotype structure of ACVR2A in order for the causative genetic variant to be identified.
\end{abstract}

Keywords: ACVR2A, Pre-eclampsia, SNP, Activin A

\section{Background}

Pre-eclampsia (PE) is a serious disorder of human pregnancy characterised by new-onset hypertension and proteinuria after 20 weeks of gestation. PE may lead to multi-organ dysfunction and rarely, to a life-threatening convulsive condition, eclampsia (E). PE affects $3-5 \%$ of pregnancies worldwide and occurs in all ethnic groups. It is considered a feto-maternal problem, immunologyrelated poor placentation playing a role in the etiology [1], The development and the progression of the disease are unpredictable, and no effective therapy is currently available apart from the delivery of the placenta [2]. In the mother, PE is associated with an increased risk of cardiovascular disease (CVD) in later life [2,3].

\footnotetext{
* Correspondence: hannele.laivuori@helsinki.fi

'Department of Medical Genetics, Haartman Institute, University of Helsinki,

P.O. Box 63 (Haartmaninkatu 8), Fl-00014 Helsinki, Finland Full list of author information is available at the end of the article
}

The cell signaling protein activin A is a dimeric member of the transforming growth factor- $\beta$ (TGF- $\beta$ ) superfamily of signaling proteins. The role of TGF- $\beta$ proteins has previously been described in various cellular processes required for reproductive function including regulation of cell proliferation, differentiation and apoptosis $[4,5]$. Activin A plays a role in endothelial regulation and maternal endovascular inflammatory response [6-8]. Activin receptors type I and type II, hereafter ACVR1 and ACVR2, are barrel like transmembrane receptor proteins. Activin A binds with ACVR2 which associates with and phosphorylates ACVR1. Activin receptors are expressed in the endometrium, placental tissue, vascular endothelial cells and trophoblasts from early on in pregnancy $[9,10]$. ACVR2 is coded by the activin receptor gene $A C V R 2 A$ on chromosome 2q22 [11].

Genetic factors are a major contributor to susceptibility to PE [12]. The genetic risk of PE is considered to be complex, and the strongest evidence to date exists for
C Biomed Central 
maternal risk [13]. Linkage studies in Australian, New Zealand and Icelandic pedigrees have demonstrated a PE susceptibility locus on chromosome 2q22-23 [14,15]. $A C V R 2 A$ has been described as a putative candidate gene [16].

$\mathrm{PE} / \mathrm{E}$ has been associated with elevated maternal serum levels of activin A in several studies [17,18]. It has been suggested that a defective expression of $A C V R 2 A$ may influence activin A concentrations and thereby alter the processes of decidualisation, trophoblast invasion and remodelling of the spiral arteries [16]. A dysregulated receptor expression, i.e. downregulated $A C V R 2 A$ expression, may cause elevated activin A serum levels. Hypotetically, this might be a shared mechanism between CVD and $\mathrm{PE} / \mathrm{E}$, leading to an imbalance of anti-inflammatory and inflammatory responses [19].

Moses and al. [16] found an association between PE and a single nucleotide polymorphism (SNP) (rs1424954), located approximately 1800 bp upstream of the transcriptional start site in the $A C V R 2 A$ gene. To replicate this first finding, we analysed whether the $A$ $>G$ polymorphism on this $A C V R 2 A$ gene site would be associated with PE in a Finnish study population.

\section{Methods}

The SNP rs1424954 was genotyped in a total of 485 Finnish women with prior PE and 449 control subjects from three different study populations described below. Both primiparous and multiparous women were included in the study. In the absence of patient identifiers, Data sets 1, 2 and 3 were cross-checked for a combination of age, body mass index (BMI), and relative birth weight to exclude the possibility of double-recruitment. All subjects provided a written informed consent, and all study protocols were approved by the appropriate local Ethical Committees. In addition, the approval of the Finnish Ministry of Social Affairs and Health was obtained for the population-based study (Data set 1).

The diagnostic criteria of PE used are defined below separately for each study. Systolic blood pressure $\geq 160$ $\mathrm{mmHg}$ and/or diastolic blood pressure $\geq 110 \mathrm{mmHg}$ was classified as severe PE. The criteria for severe PE used in this study do not include the severity of proteinuria as quantitative measurements of proteinuria were not available for all cases.

Pre-pregnancy weight and height were obtained from the antenatal care records where they are in most cases recorded as reported by the mother at the first maternity clinic visit, usually before 12 weeks of gestation. BMI was defined as the pre-pregnancy weight in kilograms divided by height in meters squared $\left(\mathrm{kg} / \mathrm{m}^{2}\right)$. Small-for-gestational age (SGA) was defined as relative birth weight under -2.0 SD units (Z-score) according to Finnish standards [20].

\section{Data Set 1: Finnish population-based preeclampsia study} The cases and controls for the population-based data set were identified by combining two national registers [21]. In Finland, pregnant women are registered in the National Register of Blood Group and Blood Group Antibodies of Pregnant Women at the Finnish Red Cross Blood Service, from which 100,000 consecutive pregnant women were identified during 1997-1998. Of these, 1084 had an International Classification of Diseases (ICD-10) code for PE or eclampsia in the National Hospital Discharge Register maintained by the National Research and Development Centre for Welfare and Health. First 665 women with PE diagnosis were invited to the study and 411 (62\%) participated. After checking the case records and excluding multiple pregnancies, 226 cases with singleton pregnancies fulfilled the criteria for PE. In addition to PE patients, a random sample of women without pregnancy complications $(\mathrm{n}=1930)$ were invited to the study and $843(44 \%)$ participated. Of these, 346 women with singleton full-term pregnancies without hypertensive complications, matched as closely as possible with the cases for the province of residence, parity, and maternal age, served as controls in this study. All participants were of Finnish ethnic origin, gave blood samples for the study, and filled out questionnaires to supplement the data obtained from medical records.

PE was defined as systolic blood pressure $\geq 140$ $\mathrm{mmHg}$ and diastolic blood pressure $\geq 90 \mathrm{mmHg}$ with new-onset proteinuria $(0.3 \mathrm{~g} / \mathrm{l}$ or $\geq 0.5 \mathrm{~g} / 24 \mathrm{~h}$ or dipstick $\geq+$ representing values $\geq 0.3 \mathrm{~g} / \mathrm{l}$ ) after 20 weeks of gestation in a previously normotensive woman (slightly modified from ACOG criteria) [21,22]. The highest blood pressure values were recorded.

\section{Data Set 2: Southern Finland preeclampsia study}

Using the discharge records, we identified women who had developed severe PE and given birth in Helsinki University Central Hospital between January 1988 and April 1998 [23]. Patients with multiple pregnancies were excluded. Blood samples were collected between January 1997 and April 1998 after the index pregnancy. During the same period, blood samples were collected from control subjects with singleton deliveries in the same hospital after uncomplicated pregnancies. In total, 129 pre-eclamptic women and 103 normotensive healthy controls with no pregnancy complications were recruited. Twenty-five women were recruited as multiparas in the pre-eclamptic group. Ten women (40\%) had a previous pre-eclamptic pregnancy and two women $(8 \%)$ had a previous hypertensive pregnancy. Among the PE cases, 102 women had a systolic blood pressure $\geq$ $160 \mathrm{mmHg}$ and/or a diastolic blood pressure $\geq 110$ and 88 had proteinuria of at least $2 \mathrm{~g}$ per 24 -h urine 
collection. All subjects were of Finnish ethnic origin, lived in southern Finland and had been healthy before their first pregnancy, without evidence of renal or autoimmune diseases. At 12 weeks postpartum, all women were normotensive and proteinuria had disappeared.

The diagnostic criteria of PE used were systolic blood pressure $\geq 140 \mathrm{mmHg}$ and diastolic blood pressure $\geq 90$ mmHg with new-onset proteinuria $(\geq 0.3 \mathrm{~g} / 24 \mathrm{~h})$ after 20 weeks of gestation in a previously normotensive woman [23]. The blood pressure was confirmed by two measurements taken at least $6 \mathrm{~h}$ apart.

\section{Data Set 3: Eastern Finland preeclampsia study}

The samples of this data set were collected retrospectively from women with prior PE when primiparous who delivered at Kuopio University Hospital between January 1994 and December 1998 [24]. PE patients were identified from the Birth Registry of the City of Kuopio, contacted by telephone and asked to participate in the study and sign a consent form. Patients with multiple pregnancies were excluded. In total, samples obtained from 130 women with prior PE in a singleton pregnancy were analysed.

In this study, PE was defined as the development of hypertension and new-onset proteinuria ( $\geq 300 \mathrm{mg}$ of urinary protein per $24 \mathrm{~h}$ ). Hypertension was defined as $\geq 140 \mathrm{mmHg}$ systolic and/or $\geq 90 \mathrm{mmHg}$ diastolic pressure, when measured on two consecutive occasions at least $24 \mathrm{~h}$ apart [25]. Women with essential hypertension were excluded from the study.

\section{SNP Genotyping}

DNA was extracted using standard laboratory protocols. The ACVR2A SNP (rs1424954) was genotyped using an ABI TaqMan ${ }^{\circledR}$ Pre-Designed SNP Genotyping Assay (Applied Biosystems, Carlsbad, CA).

Polymerase chain reaction (PCR) amplification was carried out according to the manufacturer's instructions. An ABI 7500 real-time thermocycler (Applied Biosystems, Foster City, CA) was used to perform plate reading. Automated allele calling was performed by allelic discrimination plots using Applied Biosystems 7500/ 7500fast Real-Time PCR Software v.2.0 (Applied Biosystems, Carlsbad, CA).

\section{Statistical analyses}

The Hardy-Weinberg Equilibrium Calculator of the Genetic Online Encyclopedia was used to test for deviations in genotype distributions from the Hardy-Weinberg equilibrium [25]. We used Genetic Power Calculator to evaluate our ability to detect association to marker rs1424.954 (http://pngu.mgh.harvard.edu/ purcell/gpc/) assuming a PE prevalence of $3 \%$, proposed high risk allele $(G)$ frequency of 0.6 and genotypic relative risk of 1.1 for $G A$ and 1.6 for GG. With these assumptions, a sample size of 422 PE cases was estimated to result in a power $>0.8443$ when $\alpha<0.05$.

Differences in the background characteristics between the cases and controls were analysed using the Student's $t$-test or the Mann-Whitney test (continuous variables), and the Chi-square test or the Fisher's exact test (frequencies for discrete variables). Allele frequencies were calculated directly from the genotype data. Differences in the frequencies of genotypes and alleles among the multiparous and the primiparous PE cases and controls were analysed using the Chi-square test. We also tested the genotypes containing the proposed high risk allele (G), GG + AG, against the AA genotype. Logistic regression analysis was used to test the association of the sequence variant studied with the delivery of an SGA infant. $P$-value $<0.05$ was considered as statistically significant in all analyses. The statistical software used was PASW Statistics 18.0 and Prism for Windows, version 4.03, GraphPad Software Inc, La Jolla, CA, USA.

\section{Results}

The clinical characteristics of the study population are presented in Table 1 . There was no significant difference in the mean age of PE cases and controls. The cases had a higher mean BMI than the controls, delivered earlier and their infants had a lower birth weight. Pre-gestational and gestational diabetes were slightly more common in the primiparous PE cases than in the primiparous control women.

Among the PE patients, $53.7 \%$ delivered before 37 weeks of gestation, whereas among the controls the rate of preterm delivery was $0.7 \%(p<0.001)$. SGA babies were more common among the PE patients $(28.5 \%)$ compared with the controls $(0.4 \%)(p<0.001)$. Out of all PE patients, $62 \%$ had severe PE.

We did not find any significant differences between the PE cases and controls regarding the genotype or allele frequencies of the SNP rs1424954 in the primiparous, multiparous or combined samples (Table 2). No differences in the frequency of PE were found between the subjects having the proposed risk allele G (GG and AG genotypes), compared with those homozygous for the A-allele $(p=0.882)$. In logistic regression analysis, when using the AA genotype as a reference, the odds ratio (OR) for PE was 0.99 (95\%CI:0.65,1.52) for the subjects with the GG genotype and 1.07 (95\%CI:0.701.63) for those with the AG genotype, but the results were not statistically significant.

There were no differences in the genotype $(p=0.570)$ or allele $(p=0.414)$ frequencies of interest between the women who delivered an SGA infant and those with a non-SGA baby. The GG or the AG genotypes were not associated with the delivery of an SGA infant (OR for 
Table 1 Clinical characteristics of Finnish pre-eclampsia (PE) patients and control subjects (mean and standard deviation SD) combined from Finnish population based Data set (Data set 1), Southern Finland PE Data set (Data set 2) and Eastern Finland PE Data Set (Data set 3)

\begin{tabular}{|c|c|c|c|c|c|c|c|c|c|c|c|c|c|c|}
\hline & \multicolumn{6}{|c|}{ Pre-eclampsia } & \multicolumn{6}{|c|}{ Controls } & \multirow{3}{*}{$\begin{array}{c}\text { Primiparous } \\
p^{*}\end{array}$} & \multirow{3}{*}{$\begin{array}{c}\text { Multiparous } \\
p^{*}\end{array}$} \\
\hline & \multicolumn{3}{|c|}{$\begin{array}{c}\text { Primiparous }(n= \\
321)\end{array}$} & \multicolumn{3}{|c|}{$\begin{array}{c}\text { Multiparous }(n= \\
164)\end{array}$} & \multicolumn{3}{|c|}{$\begin{array}{c}\text { Primiparous }(n= \\
264)\end{array}$} & \multicolumn{3}{|c|}{$\begin{array}{c}\text { Multiparous }(n= \\
185)\end{array}$} & & \\
\hline & $\mathbf{N}$ & Mean & SD & $\mathbf{N}$ & Mean & SD & $\mathrm{N}$ & Mean & SD & $\mathbf{N}$ & Mean & SD & & \\
\hline Age (years) & 321 & 27.7 & 5.4 & 164 & 31.8 & 5.2 & 264 & 27.6 & 4.7 & 185 & 31.0 & 4.9 & 0.374 & 0.177 \\
\hline $\mathrm{BMI}\left(\mathrm{kg} / \mathrm{m}^{2}\right)$ & 302 & 23.8 & 4.5 & 162 & 24.6 & 4.4 & 264 & 22.2 & 3.1 & 185 & 23.2 & 3.7 & $<0.001$ & 0.002 \\
\hline Systolic BP (mmHg) & 315 & 167.0 & 18.4 & 154 & 169.6 & 17.1 & 80 & 118.6 & 9.0 & 22 & 119.1 & 11.9 & $<0.001$ & $<0.001$ \\
\hline Diastolic BP (mmHg) & 316 & 105.7 & 10.1 & 154 & 105.1 & 10.4 & 80 & 73.6 & 7.8 & 22 & 72.2 & 8.9 & $<0.001$ & $<0.001$ \\
\hline Birth weight (g) & 320 & 2399.9 & 934.6 & 162 & 2382.6 & 863.2 & 264 & 3537.8 & 404.0 & 185 & 3635.0 & 412.8 & $<0.001$ & $<0.001$ \\
\hline Relative birth weight (SD) & 311 & -1.4 & 1.3 & 160 & -1.2 & 1.3 & 262 & -0.2 & 0.8 & 183 & 0.0 & 0.8 & $<0.001$ & $<0.001$ \\
\hline \multirow[t]{2}{*}{ Gestational age at birth (weeks) } & 315 & 35.7 & 3.9 & 164 & 35.5 & 3.5 & 264 & 39.9 & 1.5 & 185 & 40.0 & 1.2 & $<0.001$ & $<0.001$ \\
\hline & $\mathrm{N}$ & $\%$ & & $\mathrm{~N}$ & $\%$ & & $\mathrm{~N}$ & $\%$ & & $\mathrm{~N}$ & $\%$ & & $p^{* *}$ & $p^{* *}$ \\
\hline Gestational diabetes & 16 & 5.4 & & 7 & 4.3 & & 5 & 1.9 & & 12 & 6.5 & & 0.046 & 0.362 \\
\hline Pre-gestational diabetes & 8 & 2.7 & & 5 & 3.1 & & 1 & 0,0 & & 1 & 0.5 & & 0.046 & 0.103 \\
\hline
\end{tabular}

* Student's t-test or Mann-Whitney test. ** Chi-square test or Fisher's exact test

GG: 0.93 (95\%CI: 0.50,1.72), OR for AG: 1.15 (0.62,2.11), $\mathrm{AA}=$ reference).

\section{Discussion}

In this replication study, we could not confirm the association of the candidate SNP rs1424954 to PE. The role of $A C V R 2 A$ in PE has been the subject of several investigations in recent years. The gene was originally identified as a strong candidate by Moses et al. [16] who also described the association of rs1424954 to PE in 34 PE families of Australian and New Zealand origin. However, this finding failed to replicate in a larger cohort of 74 Australia/New Zealand families with a history of PE, possibly due to the greater genetic heterogeneity of the larger sample size [26]. Roten et al. [27] experienced technical difficulties with the replication of rs1424954 in a Norwegian retrospective population-based cohort, but were still able to indicate a nominal association of the $A C V R 2 A$ gene with PE. Since the original finding of an association to rs1424954, other SNPs have been suggested $[26,27]$. However, due to inconclusive results we selected to search for the association of the rs1424954 to PE in a group of Finnish PE patients with severe placental implications as indicated by the high incidence of preterm deliveries.

The PE cases in our study met strict diagnostic criteria PE in an attempt to avoid the challenges posed by genetic heterogeneity as described by Fitzpatrick et al. [26]. Due to the relative historic isolation, the Finnish population bears characteristics of a founder population with the potential of reduced genetic heterogeneity [28]. However, the risk of population stratification brought

Table 2 ACVR2A genotypes and allele counts among Finnish pre-eclampsia (PE) patients and control subjects combined from Finnish population based Data set (Data set 1), Southern Finland PE Data set (Data set 2) and Eastern Finland PE Data Set (Data set 3)

\begin{tabular}{|c|c|c|c|c|c|c|c|c|c|}
\hline & & Pre-eclampsia & & & Controls & & & $p^{* *}$ & \\
\hline & $\begin{array}{c}\text { Primiparous } \\
(n=321)\end{array}$ & $\begin{array}{c}\text { Multiparous } \\
(n=164)\end{array}$ & $\begin{array}{l}\text { Combined ( } n \\
=485)\end{array}$ & $\begin{array}{l}\text { Primiparous } \\
(n=264)\end{array}$ & $\begin{array}{l}\text { Multiparous } \\
(n=185)\end{array}$ & $\begin{array}{l}\text { Combined } \\
(\mathrm{n}=449)\end{array}$ & Primiparous & Multiparous & Combined \\
\hline Genot & & & & & & & & & \\
\hline$\overline{G G}$ & 134 & 67 & 201 & 108 & 87 & 195 & & & \\
\hline$\overline{\mathrm{AG}}$ & 148 & 70 & 218 & 121 & 76 & 197 & & & \\
\hline$\overline{\mathrm{AA}}$ & 32 & 24 & 56 & 33 & 21 & 54 & 0.468 & 0.660 & 0.871 \\
\hline$N / A^{*}$ & 7 & 3 & 10 & 2 & 1 & 3 & & & \\
\hline Alleles & (Frequency) & & & & & & & & \\
\hline $\bar{G}$ & 416 & 204 & 620 & 337 & 250 & 587 & & & \\
\hline$A$ & 212 & 118 & 330 & 187 & 118 & 305 & 0.493 & 0.205 & 0.806 \\
\hline
\end{tabular}

* Genotyping failed ** Chi-square test 
about by inclusion of the Eastern Finland case cohort exists [28]. One weakness of our study is that it combines three retrospectively collected data sets in which the extent of coded information available varies. Therefore, for example, we did not have access to data on the status of previous pregnancies of multiparous women.

The above-mentioned studies have supported the role of $A C V R 2 A$ in PE, although conclusive evidence is still lacking. Fitzpatrick et al. identified nine new SNPs in the ACVR2A region [26]. This enabled the description of defined Linkage Disequilibrium (LD) patterns which were subsequently replicated in the Norwegian population $[26,27]$. We hypothesise that while the haplotypes in the region are conserved, the causative variant may vary among populations with differing genetic backgrounds. Indeed, the SNP rs1424954 lies more than 1.5 $\mathrm{kb}$ upstream of the $A C V R 2 A$ gene. We postulate that a regulatory region with population-specific polymorphisms in this locus might explain the previously reported association to PE [16]. It is possible that the causative variant lies among one of the other haploblock structures previously described in the ACVR2A gene [27]. Furthermore, we hypothesise that the predisposing genetic effect of $A C V R 2 A$ in $\mathrm{PE}$ is, in fact, a collection of associated alleles rendering the effect of individual SNPs undetectable in even cohorts with the strictest inclusion criteria.

\section{Conclusions}

The locus 2q22-23, where $A C V R 2 A$ is located, has been indicated as a susceptibility locus for PE in several population cohorts with different ancestral background. The functional description of the gene continues to attract PE investigators towards $A C V R 2 A$. The first reported candidate SNP from previous studies, rs1424954, was not replicated in Finnish patients with PE. Thus far a common causative variant has not been identified. Further studies in the field are important to increase the understanding of the role of $A C V R 2 A$ in the pathogenesis of PE

\footnotetext{
Acknowledgements

We wish to thank all women who participated in this study. We also acknowledge laboratory technician Hanna Nurmi for her excellence in carrying out genotyping. Support for this work has been provided by The Academy of Finland, The Finnish Medical Foundation, University of Helsinki, Helsinki University Central Hospital EVO-funds, Päivikki and Sakari Sohlberg Foundation, and Jane and Aatos Erkko Foundation.
}

\section{Author details}

'Department of Medical Genetics, Haartman Institute, University of Helsinki, P.O. Box 63 (Haartmaninkatu 8), Fl-00014 Helsinki, Finland. 'Women's Health, Research Programs Unit, University of Helsinki, Helsinki, Finland. ${ }^{3}$ Department of Obstetrics and Gynaecology, Helsinki University Central Hospital, Helsinki, Finland. ${ }^{4}$ The National Graduate School of Clinical Investigation, University of Helsinki, Helsinki, Finland. ${ }^{5}$ Department of Haemostasis, Finnish Red Cross Blood Service, Helsinki, Finland. 'Department of Obstetrics and Gynaecology,
Kuopio University Hospital, Kuopio, Finland. University of Eastern Finland, Kuopio, Finland.

\section{Authors' contributions}

IL analysed the results and drafted the manuscript. MK described patient material and participated in analysing of the results and drafting of the manuscript. S Heino supervised the laboratory analyses. LH provided Data set 1 including the DNA samples for this work. S Heinonen provided samples of Data set 3 for this work. HL designed and initiated the study, provided DNA samples from Data set 2 and participated in drafting of the manuscript. All authors read and approved of the final manuscript.

\section{Competing interests}

The authors declare that they have no competing interests.

Received: 5 August 2011 Accepted: 19 December 2011

Published: 19 December 2011

\section{References}

1. Robillard PY, Dekker G, Chaouat G, Hulsey TC, Saftlas A: Epidemiological studies on primipaternity and immunology in preeclampsia-a statement after twelve years of workshops. J Reprod Immunol 2011, 89(2):104-117.

2. Roberts JM, Pearson G, Cutler J, Lindheimer M: Summary of the NHLBI working group on research on hypertension during pregnancy. Hypertension 2003, 41(3):437-445.

3. Bellamy L, Casas J, Hingorani AD, Williams DJ: Pre-eclampsia and risk of cardiovascular disease and cancer in later life: systematic review and meta-analysis. BMJ 2007, 335(7627):974.

4. Jones RL, Stoikos C, Findlay JK, Salamonsen LA: TGF-\{beta\} superfamily expression and actions in the endometrium and placenta. Reproduction 2006, 132(2):217-232

5. Florio P, Gabbanini M, Borges LE, Bonaccorsi L, Pinzauti S, Reis FM, Boy Torres P, Rago G, Litta P, Petraglia F: Reviews: activins and related proteins in the establishment of pregnancy. Reprod Sci 2010, 17(4):320-330.

6. Hoegh AM, Borup R, Nielsen FC, Sørensen S, Hviid TVF: Gene Expression Profiling of Placentas Affected by Pre-Eclampsia. J Biomed Biotechnol 2010, 2010:11, Article ID 787545.

7. Phillips DJ, de Kretser DM, Hedger MP: Activin and related proteins in inflammation: not just interested bystanders. Cytokine Growth Factor Rev 2009, 20(2):153-164.

8. Breit S, Ashman K, Wilting J, Rössler J, Hatzi E, Fotsis T, Schweigerer L: The $\mathrm{N}$-myc oncogene in human neuroblastoma cells: down-regulation of an angiogenesis inhibitor identified as activin A. Cancer Res 2000, 60(16):4596-4601.

9. Peng C, Huang T, Jeung E, Donaldson C, Vale W, Leung P: Expression of the type II activin receptor gene in the human placenta. Endocrinology 1993, 133(6):3046-3049.

10. Schneider-Kolsky ME, Manuelpillai U, Waldron K, Dole A, Wallace EM: The distribution of activin and activin receptors in gestational tissues across human pregnancy and during labour. Placenta 2002, 23(4):294-302.

11. Bondestam J, Horelli-Kuitunen N, Hildén K, Ritvos O, Aaltonen J: Assignment of ACVR2 and ACVR2B the human activin receptor type II and IIB genes to chromosome bands $2 q 22.2-q 23.3$ and 3p22 and the human follistatin gene (FST) to chromosome $5 q 11.2$ by FISH. Cytogenet Cell Genet 1999, 87(3-4):219-220.

12. Salonen Ros H, Lichtenstein P, Lipworth L, Cnattingius S: Genetic effects on the liability of developing pre-eclampsia and gestational hypertension. Am J Med Genet 2000, 91(4):256-260.

13. Cnattingius $S$, Reilly $M$, Pawitan $Y$, Lichtenstein $P$ : Maternal and fetal genetic factors account for most of familial aggregation of preeclampsia: A population-based Swedish cohort study. Am J Med Genet Part A 2004, 130A(4):365-371.

14. Moses EK, Lade JA, Guo GL, Wilton AN, Grehan M, Freed K, Borg A, Terwilliger JD, North R, Cooper DW, Brennecke SP: A genome scan in families from Australia and New Zealand confirms the presence of a maternal susceptibility locus for pre-eclampsia, on chromosome 2. Am J Hum Genet 2000, 67(6):1581-1585

15. Arngrímsson R, Siguróaróóttir $S$, Frigge ML, Bjarnaóóttir RI, Jónsson T, Stefánsson H, Baldursdóttir Á, Einarsdóttir AS, Palsson B, Snorradôttir S, Lachmeijer AMA, Nicolae D, Kong A, Bragason BT, Gulcher JR, Geirsson RT, Stefánsson K: A Genome-Wide Scan Reveals a Maternal Susceptibility 
Locus for Pre-Eclampsia on Chromosome 2p13. Hum Mol Genet 1999, 8(9):1799-1805.

16. Moses EK, Fitzpatrick E, Freed KA, Dyer TD, Forrest S, Elliott K, Johnson MP, Blangero J, Brennecke SP: Objective prioritization of positional candidate genes at a quantitative trait locus for pre-eclampsia on 2q22. Mol Hum Reprod 2006, 12(8):505-512.

17. Laivuori H, Kaaja R, Turpeinen U, Stenman U, Ylikorkala O: Serum activin A and inhibin A elevated in pre-eclampsia: no relation to insulin sensitivity. BJOG: Int J Obstet Gynaecol 1999, 106(12):1298-1303.

18. Yu J, Shixia C, Wu Y, Duan T: The study of inhibin A, activin A, placental growth factor and uterine artery Doppler pulsatility index to predict preeclampsia. Ultrasound Obst Gynecol 2010, 37(5):528-533.

19. Smith C, Yndestad A, Halvorsen B, Ueland T, Wæhre T, Otterdal K, Scholz H, Endresen K, Gullestad L, Frøland SS, Damås JK, Aukrust P: Potential antiinflammatory role of activin $\mathrm{A}$ in acute coronary syndromes. $\mathrm{J}$ Am Coll Cardiol 2004, 44(2):369-375.

20. Pihkala J, Hakala T, Voutilainen P, Raivio K: Characteristic of recent fetal growth curves in Finland. Duodecim 1989, 105(18):1540-1546.

21. Hiltunen L, Laivuori H, Rautanen A, Kaaja R, Kere J, Krusius T, Paunio M, Rasi $V$, Blood group $A B$ and factor $V$ Leiden as risk factors for preeclampsia: A population-based nested case-control study. Thromb Res 2009, 124(2):167-173.

22. ACOG Committee on Obstetric Practice: ACOG practice bulletin, Diagnosis and management of preeclampsia and eclampsia. Int J Gynaecol Obstet 2002, 77(1):67-75.

23. Laivuori H, Kaaja R, Ylikorkala O, Hiltunen T, Kontula K: $677 \mathrm{C}>\mathrm{T}$ polymorphism of the methylenetetrahydrofolate reductase gene and preeclampsia. Obstet Gynecol 2000, 96(2):277-280.

24. Saarela T, Hiltunen M, Helisalmi S, Heinonen S, Laakso M: Tumour necrosis factor-a gene haplotype is associated with pre-eclampsia. Mol Hum Reprod 2005, 11(6):437-440.

25. Rodriguez S, Gaunt TR, Day INM: Hardy-Weinberg Equilibrium Testing of Biological Ascertainment for Mendelian Randomization Studies. American Journal of Epidemiology 2009, 169(4):505-514.

26. Fitzpatrick E, Johnson MP, Dyer TD, Forrest S, Elliott K, Blangero J, Brennecke SP, Moses EK: Genetic association of the activin A receptor gene (ACVR2A) and pre-eclampsia. Mol Hum Reprod 2009, 15(3):195-204.

27. Roten LT, Johnson MP, Forsmo S, Fitzpatrick E, Dyer TD, Brennecke SP, Blangero J, Moses EK, Austgulen R: Association between the candidate susceptibility gene ACVR2A on chromosome 2 q22 and pre-eclampsia in a large Norwegian population-based study (the HUNT study). Eur I Hum Genet 2009, 17(2):250-257.

28. Jakkula $E$, Rehnström $\mathrm{K}$, Varilo $T$, Pietiläinen $\mathrm{OPH}$, Paunio $\mathrm{T}$, Pedersen $\mathrm{NL}$, deFaire U, Järvelin M, Saharinen J, Freimer N, Ripatti S, Purcell S, Collins A, Daly MJ, Palotie A, Peltonen L: The genome-wide patterns of variation expose significant substructure in a founder population. Am J Hum Genet 2008, 83(6):787-794.

doi:10.1186/1756-0500-4-545

Cite this article as: Lokki et al: Association of the rs 1424954

polymorphism of the ACVR2A gene with the risk of pre-eclampsia is not replicated in a Finnish study population. BMC Research Notes 2011 4:545.

\section{Submit your next manuscript to BioMed Central and take full advantage of:}

- Convenient online submission

- Thorough peer review

- No space constraints or color figure charges

- Immediate publication on acceptance

- Inclusion in PubMed, CAS, Scopus and Google Scholar

- Research which is freely available for redistribution

Submit your manuscript at www.biomedcentral.com/submit
Biomed Central 